\title{
Score Analysis and Interpretation of a School-Based Placement Test on the Basis of the CSE
}

\author{
Juntao Cheng ${ }^{1}$ and Huijie $\mathrm{Li}^{1, *}$ \\ ${ }^{1}$ School of International Studies, Harbin Institute of Technology, Harbin, Heilongjiang 150001, China \\ *Corresponding author.Email: lihuijiehit@126.com
}

\begin{abstract}
The newly developed China's Standards of English Language Ability (the CSE) defines the levels of English ability of Chinese learners. As one of the practical studies to support its feasibility, this study aims to draw a picture of Harbin Institute of Technology (HIT) freshmen's English language proficiency with the CSE as yardstick by applying it to the placement test for freshmen at HIT. This study compares the original grouping strategy with the new CSE-based strategy and speculates the possible reasons of students' test performance according to the current state of English education in China and with the backing of previous relevant research. A combination of qualitative and quantitative research method was adopted in this research, and test data were collected from "iFlyTEK" online test platform and analyzed by SPSS. The main results are as follows: First, when grouped according to separate section of the test paper for specific English abilities, students were placed from level 4 to 8 of the CSE with the best performance in the reading section, the worst in listening section; when grouped according to the average point of listening, reading and writing, students were placed among the CSE 3 to 6 . Second, the CSE-based grouping strategy is valid. Meanwhile, it is much closer to the actual English proficiency of students tested than the traditional method. Third, students' performance in listening mainly results from the imbalance of Chinese high-school English teaching and students' unfamiliarity to the test items and online test platform. This study is innovative in that it serves as a preparation for the next stage of our research which is to develop a new terminal final test for freshmen at HIT based on the CSE, and ameliorates the assessment of English proficiency of students in HIT.

Keywords: the CSE, placement test, score analysis, HIT
\end{abstract}

\section{INTRODUCTION}

The CSE stands for China's Standards of English Language Ability, an officially unified, standardized scale for assessing English proficiency of Chinese English learners. It was constructed on the basis of Bachman's "Communicative Language Ability" model, mainly composed of the following sections: an overall scale of English proficiency; branch scales for listening, reading comprehension, oral expression, written expression, organizational competence, pragmatic ability, interpretation competence and translation competence; the detailed description of abilities involved in these aspects; and finally, a self-assessment scale for English learners. Developers of the CSE designed descriptors to specify the ability of English learners and users. In the CSE, their English proficiency development is divided into nine levels of three stages: elementary (Level 1-3), intermediate (Level 4-6), and advanced (Level 7-9). [1]

The CSE aims to provide guidance for both English learners and educators. For instance, English learners can adjust their learning methods in time with the help of the description of English proficiency at all levels on the CSE, enhancing their self-learning ability and adaptability to various English tests. Educational institutions and test developers are able to design English curriculums and tests according to learner's different needs, motivation and potential. [2]

The HIT school-based placement test for freshmen is a compulsory test for newly-enrolled student of all schools, developed out of HIT's desire to improve students' highlevel English proficiency and enables them to pursue further education abroad in their college years, which is an important part of bringing HIT education in line with the international standards. In nature, this placement test is a critical step of a revamp project of the English final exam for freshman. In the past, the final exam was quite similar to CET 4 and 6 in test items, and now these questions don't seem difficult enough for certain students to demonstrate their actual English proficiency. Apart from this, the university adopted a rather rough approach to classify students into three large groups: basic level, developing level and advanced level, according to a proportion in population of $25 \%, 50 \%$ and $25 \%$. Therefore, the original final exam must be revamped, and the placement test was the most fundamental part of this project. It sees to it that students were classified into more specific groups according to the scientific scale of the CSE, and an overall picture of their strengths and weaknesses in English learning can be drawn. 


\section{LITERATURE REVIEW}

\subsection{The Development of CSE}

The CSE was developed by National Education Examinations Authority and Department of Language Information Management, Ministry of Education of the People's Republic of China. In February 2018, the CSE was publicly released and officially implemented on June 1, 2018 as the language standard of the National Language Standard Commission of the People's Republic of China (NLSCPRC). Due to its large cardinal number of English learners, there is a strong demand for English test and English proficiency assessments in China. However, China's original English tests have a rather low international recognition, and currently there is no test in China that can be fully integrated with the international standards. The main obstacle facing test developers is the lack of an original, unified standard for evaluating EFL learners' English proficiency in China. [3] Thus, to make China's English tests in line with international standards became the fundamental motivation for the development of the CSE.

The alignment of the CSE with international standards and the continuing revision to it were carried out simultaneously. To improve its adaptability and accuracy, many researchers investigated on the alignment of the CSE with IETLS, TOFEL, and Common European Framework of Reference (CEFR) were carried out. For example, in Peng's study, all 467 CEFR descriptors and 104 CSE anchor descriptors were used in 15 questionnaires, rated by 5441 teachers and 23,260 students, and analyzed by Rasch analysis, and respectively joined each level of the two scales. This study strengthened the CSE and has great implications for language teaching, learning, and assessment for different stakeholders in China and abroad. [4]

\subsection{Research on the CSE}

Researches on the CSE mainly concentrate on three fields of study, the content, application and prof of validity of the CSE. First, regarding the content, some domestic scholars have carried out studies on its descriptors. For example, Zhu Zhengcai (2021) made a comparative analysis of three statistical test modes for the research on differential item functioning. The paper also makes a semantic analysis of the biased descriptors and makes a preliminary attribution of the reasons for them, which provides a basis for the modification of the descriptors of the CSE [5]. Meanwhile, domestic scholar Zhou Yanqiong (2021) conducted a study on the validity of reading strategy descriptors in the CSE from the perspective of Rasch measurement model. The results showed that the reading strategy descriptors fit well, but some descriptors had necessity to be revised or deleted in order to optimize their level representativeness. [6]
Second, the application of the CSE. The major concentration of domestic research lies in the role of the CSE in English teaching at all levels and the investigation of students' English proficiency based on the CSE, involving reading, writing, speaking, listening and constructional abilities. For instance, Zhang Wenjing (2020) in her thesis investigated the impact of the CSE self-assessment scale on junior middle school students' English score, and found that the self-assessment scale in the CSE can significantly improve students' English scores in English tests and learning reflection ability, and proved the CSE's effect in improving the quality of teaching. [7] Third, alignment study between the CSE and English proficiency tests at all levels. In 2020, Zhou Bi conducted an alignment study of the CSE and the reading section of National Matriculation English Test (NMET) to establish the linking relationship between them. The conclusion of this study is that NMET reading can be roughly matched to grade 4 and grade 5 of the CSE reading scale [8]. In the same year, Wang Hua, connected the CSE with the Shanghai Jiao Tong University English Proficiency Test (SJTU-EPT), and found that the test could be linked to level 4 to level 8 of the CSE. [9] The above studies were merely a small part of what it needs to be done for the generalization of the CSE.

\section{METHODOLOGY}

\subsection{Implement of the Test}

The test took place on September 7, 2021, which was the first official run for this placement test. All students were required to register an account on the online platform "iFlyTEK examination", and complete the test online with their own computers connected to the campus network. The listening material was played by campus radio, and students receive it with single standard earphones. Before the official test, there was an online trial test to help the students get familiar to the platform and the procedures of an online test. 2914 freshman students from 6 clusters of schools participated in the test, of which 2912 are valid papers. The length of the test time was 140 minutes: 40 minutes for listening (30 minutes for listening, 10 minutes for transcribing answers); 60 minutes for reading; and 40 minutes for writing. The test is composed of released original IELTS test items without the oral test section and one of the compositions (Task 1 of IELTS test). The distribution of scores was 40 points for 40 items of listening, 40 points of 40 items of reading and 9 points of writing, 89 points in total. The writing section was scored according to 9-band scoring system, allowing only half points and integer points.

\subsection{The Analysis of Test Results.}

First, students' test scores were converted into the IELTS band score scale based on the IELTS standard of the 
number of correct items in each section. Since the alignment of the CSE with IELTS had completed and been examined by numerous previous researches, students' position on the CSE scale can be spotted according to the alignment between the CSE and IELTS, and according to which, researchers may preliminarily determine students' English proficiency as well as the population and proportion of students on each level. However, due to the limitation of implementation conditions of the test, the oral test was not included in the placement test, so that at the present stage, researchers have no choice but to take the average point of listening, reading and writing as students' final score, leading to inaccuracy in converting test scores into the CSE levels. Therefore, researchers applied two grouping strategies: one is to rate students according to three separate abilities tested, namely listening, reading and writing proficiency. With this method, students range from the CSE 3 to 8 . The other is according to the average point of these three sections, and students range from the CSE 3 to 7. CSE 3 in this case stands for all students below the level of CSE 4.

Next, the reliability of the paper and the test scores will be analyzed by statistic procedures in SPSS. Currently the second grouping strategy was adopted in this procedure.

\section{RESULTS AND DISCUSSION}

\subsection{Results}

The following are some critical figures about the test paper and test result: the highest score was 83.5 out of 89 , and the lowest was 4 out of 89 . The average total point was 41.1, the

average point in IELTS band score scale was 4.7 in listening, 5.55 in reading and 4.13 in writing. The whole group has a

rather low pass rate of $16.31 \%$

The difficulty of the paper was $\mathrm{L}=0.46$, acquired by the average student score divided by total test score, which is quite in the middle, indicating that the test paper is of moderate difficulty and may be challenging for certain students. The reliability of the paper was Cronbach Alpha $=.832$, which means that this paper was well designed with good internal consistency between sections. The following chart shows the number of students on each CSE level of the placement test, adopting the two grouping strategies.

Table 1 General Statistics of Sections of the Placement Test Paper

\begin{tabular}{|c|c|c|c|c|c|c|}
\hline & CSE 3 & CSE 4 & CSE 5 & CSE 6 & CSE 7 & $\begin{array}{c}\text { CSE 8 and } \\
\text { above }\end{array}$ \\
\hline Listening & 1576 & 827 & 281 & 176 & 43 & 9 \\
\hline Reading & 216 & 894 & 578 & 953 & 175 & 96 \\
\hline Writing & 952 & 994 & 741 & 217 & 8 & 0 \\
\hline Average & 954 & 1349 & 342 & 234 & 33 & 0 \\
\hline
\end{tabular}

It can be observed that the students' abilities were highly imbalanced. Their performance in the listening section was the worst compared to in the reading and writing section, which was roughly consistent with the researchers' expectancy.

Next, researchers tested the reasonability and validity of the grouping strategy with One-way ANOVA analysis. As mentioned above, currently, grouping strategy based on the average point of listening, reading and writing was tested. In the Post Hoc analysis, with the total point as the dependent, each group was compared to every other group and the significance were all much lower than .05 , demonstrating a significant difference between the groups.

Table 2 One-way ANOVA Analysis of the CSE Grouping

\begin{tabular}{|c|c|c|c|c|c|c|}
\hline \multicolumn{7}{|c|}{ Total Points } \\
\hline & \multicolumn{2}{|c|}{$\begin{array}{c}\text { Sum of } \\
\text { Squares }\end{array}$} & df & $\begin{array}{c}\text { Mean } \\
\text { Square }\end{array}$ & $\mathbf{F}$ & Sig. \\
\hline $\begin{array}{c}\text { Between } \\
\text { Groups }\end{array}$ & \multicolumn{2}{|c|}{319562.626} & 4 & 79890.656 & 1856.910 & .000 \\
\hline $\begin{array}{l}\text { Within } \\
\text { Groups }\end{array}$ & \multicolumn{2}{|c|}{125069.123} & 2907 & 43.023 & & \\
\hline Total & \multicolumn{2}{|c|}{444631.749} & 2911 & & & \\
\hline \multicolumn{7}{|c|}{$\begin{array}{l}\text { Post Hoc } \\
\text { Dependent: Total points }\end{array}$} \\
\hline \multicolumn{7}{|c|}{ Tamhane } \\
\hline \multirow[b]{2}{*}{\begin{tabular}{|c|} 
(I) CSE \\
grouping
\end{tabular}} & \multirow[b]{2}{*}{$\begin{array}{l}\text { (J) CSE } \\
\text { grouping }\end{array}$} & \multirow{2}{*}{$\begin{array}{c}\text { Mean } \\
\text { Difference } \\
\text { (I-J) }\end{array}$} & \multirow[b]{2}{*}{ e } & \multirow[b]{2}{*}{ Sig. } & \multicolumn{2}{|c|}{$\begin{array}{c}\text { 95\% Confidence } \\
\text { Interval }\end{array}$} \\
\hline & & & & & $\begin{array}{c}\text { Upper } \\
\text { Bound }\end{array}$ & $\begin{array}{l}\text { Lower } \\
\text { Bound }\end{array}$ \\
\hline \multirow{4}{*}{3.00} & 4.00 & $-11.64104 *$ & $* .2903$ & \begin{tabular}{|l|l|}
37 & .000 \\
\end{tabular} & -10.8272 & -12.4549 \\
\hline & 5.00 & $-23.43198^{*}$ & $* .3749$ & \begin{tabular}{|l|l|}
95 & .000 \\
\end{tabular} & -22.3792 & \begin{tabular}{|l|}
-24.4848 \\
\end{tabular} \\
\hline & 6.00 & $-32.89925^{*}$ & $* .4305$ & \begin{tabular}{l|l|}
55 & .000 \\
\end{tabular} & -31.6876 & -34.1109 \\
\hline & 7.00 & $-45.27182^{*}$ & \begin{tabular}{l|l|}
$* .7474$ \\
\end{tabular} & \begin{tabular}{|l|l|}
42 & .000
\end{tabular} & -43.0535 & -47.4902 \\
\hline \multirow{4}{*}{4.00} & 3.00 & 11.64104* & * .2903 & \begin{tabular}{|l|l|}
37 & .000 \\
\end{tabular} & 12.4549 & 10.8272 \\
\hline & 5.00 & $-11.79094^{*}$ & $* .3500$ & \begin{tabular}{l|l}
06 & .000 \\
\end{tabular} & -10.8074 & -12.7745 \\
\hline & 6.00 & $-21.25821^{*}$ & * .4090 & \begin{tabular}{|l|l|}
06 & .000
\end{tabular} & -20.1059 & -22.4105 \\
\hline & 7.00 & $-33.63078^{*}$ & $* .7352$ & \begin{tabular}{|l|l|}
25 & .000 \\
\end{tabular} & -31.4397 & -35.8219 \\
\hline \multirow{4}{*}{5.00} & 3.00 & $23.43198^{*}$ & * .3749 & \begin{tabular}{l|l}
95 & .000 \\
\end{tabular} & 24.4848 & 22.3792 \\
\hline & 4.00 & 11.79094* & \begin{tabular}{l|l}
$* .3500$ \\
\end{tabular} & \begin{tabular}{l|l|}
06 & .000
\end{tabular} & 12.7745 & 10.8074 \\
\hline & 6.00 & $-9.46727^{*}$ & * .4728 & \begin{tabular}{l|l|}
86 & .000 \\
\end{tabular} & -8.1375 & \begin{tabular}{|l|}
-10.7970 \\
\end{tabular} \\
\hline & 7.00 & $-21.83985^{*}$ & $* .7725$ & \begin{tabular}{l|l}
57 & .000
\end{tabular} & -19.5634 & -24.1162 \\
\hline \multirow{4}{*}{6.00} & 3.00 & \begin{tabular}{|l}
$32.89925^{*}$ \\
\end{tabular} & * .4305 & \begin{tabular}{l|l}
55 & .000
\end{tabular} & 34.1109 & 31.6876 \\
\hline & 4.00 & $21.25821^{*}$ & * .4090 & \begin{tabular}{l|l|}
06 & .000 \\
\end{tabular} & 22.4105 & 20.1059 \\
\hline & 5.00 & 9.46727* & \begin{tabular}{l|l} 
& .4728 \\
\end{tabular} & \begin{tabular}{l|l|}
86 & .000 \\
\end{tabular} & 10.7970 & 8.1375 \\
\hline & 7.00 & $-12.37257^{*}$ & \begin{tabular}{l|l}
$*$ & .8010 \\
\end{tabular} & \begin{tabular}{l|l}
03 & .000 \\
\end{tabular} & -10.0281 & -14.7170 \\
\hline \multirow{4}{*}{7.00} & 3.00 & \begin{tabular}{|l}
$45.27182^{*}$ \\
\end{tabular} & * .7474 & \begin{tabular}{l|l}
42 & .000 \\
\end{tabular} & 47.4902 & \begin{tabular}{|l|}
43.0535 \\
\end{tabular} \\
\hline & 4.00 & \begin{tabular}{|l}
$33.63078^{*}$ \\
\end{tabular} & * .7352 & \begin{tabular}{|l|l|}
25 & .000 \\
\end{tabular} & 35.8219 & 31.4397 \\
\hline & 5.00 & $21.83985^{*}$ & * $\mid .7725$ & \begin{tabular}{l|l}
57 & .000
\end{tabular} & 24.1162 & 19.5634 \\
\hline & 6.00 & $12.37257^{*}$ & $* .8010$ & \begin{tabular}{l|l}
03 & .000 \\
\end{tabular} & 14.7170 & 10.0281 \\
\hline
\end{tabular}

\subsection{Discussion}

To start with, the possible reason of the test results. There are several conjectures over the cause of this exceptional data. First, it is commonly acknowledged that English teaching in Chinese high schools concentrate more on 
reading and writing, while listening and speaking skills were often neglected. Teaching method was single, and listening materials chosen by high school English teachers are detached from native speaker's way of communication [10]. Several regions even once removed the listening section from National College Entrance Examination. This unreasonable skill training approach led to imbalance in high school students' language competence, thus made a possible reason for the test result. Second, the differences between the IELTS and CET 4 and 6, and National College Entrance Examination lead to a psychological discrepancy among students. Students were not properly trained before receiving this placement test, and were informed about the test items only a few days before the test. The test items they were accustomed to were CET test items and National College Entrance Examination test items from all over the country, consisting of less test items in listening and reading section, and more fixed item type such as blank-filling and MCQs. In addition, the test time of National College Entrance Examination is 2 hours, 20 minutes for listening, 25 minutes for MCQs of grammar and cloze test, 40 minutes for reading, and 35 minutes for written expression; while the placement test takes 2 hours and 20 minutes, both time and item number for listening have doubled. The complexity of test items and increased test time could be a possible reason for unexpected bad performance of students in the listening section. Third, students were not familiar with the "iFlyTEK" online test platform. Since it was the first official run for this placement test, students lack systematic training in applying online test platform, which might cause the incompleteness or inaccuracy of test paper.

As for the grouping strategy, it can be observed from the ANOVA Post Hoc test analysis result that there are significant differences among the group CSE 3 to 7. This grouping method according to the IELTS band score scale placed students' positions on the CSE, greatly improved the accuracy in depicting students' English proficiency. On the other hand, the original grouping approach failed to take students with higher test scores into consideration, in this case those students who reached CSE 6 and above in the reading section, which takes about $42 \%$ of the whole. Students on these levels are the ideal results of HIT English teaching. Making as many as possible students to reach CSE 6 and above in every section of IELTS test paper is exactly what HIT English teachers are working for. Since students on CSE 4 and 5 were spotted out from all freshmen, they will be trained to adapt themselves to IELTS test items in daily college English courses so that they may reach Level 6 as soon as possible. The rest of the students will have their daily training in a combination of CET-4 and CET-6 questions and IELTS questions. With this grouping strategy, teachers are able to directly observe the gap between students' current English proficiency and our teaching goals, and embark on the develop a more individualized teaching method for students. Meanwhiles, as for the students, it enables them to self-enhance and reflect on their learning process according to specific requirement listed on each level of the CSE.

\section{CONCLUSION}

From the placement test data demonstrated above, researchers explained the cause of the placement test results, reflected on the possible disadvantages of the teaching method adopted by current Chinese high school, and concluded that the approach of grouping students according to the CSE is valid. In addition, with support of the alignment between the CSE and IELTS, this grouping strategy was more specific and scientific than the original approach according to proportion. With these results, researchers obtained a depiction of student's English proficiency, and are able to carry on the next step of our research, that is to develop a new CSE-based final exam for freshmen in HIT.

\section{ACKNOWLEDGMENT}

Our most sincere gratitude goes to the Department of Academic Affair of School of International Studies of Harbin Institute of Technology, for financial and organizational support to the revamp project of the HIT final exam for freshmen, as well as providing the necessary information and data of students tested, as well as the implement of the placement test.

\section{REFERENCES}

[1] Zeng Yongqiang. "Principles and methods of developing the reading scale of China's Standards of English.” Foreign Language World, 2017, vol. 05, pp:11. (In Chinese)

[2] Liu Jianda, Peng Chuan. "Developing scientific China's Standards of English.” Foreign Language World, 2017, vol.02, pp: 2-9. (In Chinese)

[3] Liu Jianda. “China's Standards of English Language Ability" Foreign Languages in China, 2019, vol.16(03), pp:1+11-12. (In Chinese)

[4] Peng, C., Liu, J. \& Cai, H. “Aligning China’s Standards of English Language Ability with the Common European Framework of Reference for Languages.” Asia-Pacific Edu Res (2021). DOI: https://doi.org/10.1007/s40299-021-00617-2 (In Chinese)

[5] Zhu Zhengcai, Li Junmin. “A Study on Differential Item Functioning of the descriptors of China's Standards of English Language Ability" Modern Foreign Languages, 2021, vol. 44(01). pp:113-122. (In Chinese)

[6] Zhou Yanqiong. "Validating Descriptors of the Reading Strategic Competence Subscale of CSE: Rasch 
Measurement Model Perspective" Foreign Language World 2021(01)79-87. (In Chinese)

[7] Zhang Wenjing. "A Study on the Application and Influence of Chinese English Proficiency Scale in Junior Middle School English Teaching--A Case Study of Self-assessment Scale" Diss. Qufu Normal

University, 2020.

[8] Zhou Bi. "Aligning Reading of National Matriculation English Test (NMET) with the China's English Standards (CSE) of Ability." Diss. Guangdong University of Foreign Studies, 2020.
[9] Wang Hua. "Alignment of China's English Standards (CSE) and School-based English Proficiency Test-In the Case of Shanghai Jiao Tong University English Proficiency Test (SJTU-EPT).” Foreign Language World, 2020, vol. 05, pp:72-79. (In Chinese)

[10] Mo Yun. "Research on Current Situation and Countermeasures of English Listening Teaching in Senior High School" Cathay Teachers, 2020, vol.18, pp:68-69. (In Chinese) 